\title{
Strategy Analysis on Building College New Teaching Quality Management Mode
}

\author{
Guo Xiwei \\ School of Economy and Management \\ Shenyang Aerospace University \\ Shenyang City, China
}

\begin{abstract}
Improving teaching quality and changing teaching management mode is the priority of college reform at current stage, and meanwhile, college education is also a constant subjective. Teaching quality control and management is the primary condition for guarantying teaching quality. Currently, the expansion of the college scale in our country and the inevitable demands of the development of modern society lead to new challenges to the teaching management of the colleges. On such basis, the thesis aims to find out the corresponding measures to the specific problems in our college teaching management mode to provide reference for constructing new college management mode and improve college teaching quality.
\end{abstract}

Keywords-teaching quality; management mode; strategy; new, analysis

\section{INTRODUCTION}

with the change of the times and the development of the society, we need to change the traditional teaching mode in many majors to keep up with the times. Now there exist many problems in the teaching process to be immediately solved. The rapid development of modern society has imposed new standards on talent quality and made the traditional college education management mode no longer able to meet the development of modern society, promoting some whole new teaching concepts and mode that can better conform to the society. Besides paying attention to cultivating the professional skills of the students, it shall make sure modern college education can suit the human quality and economic development, making the graduates better meet the demands of social development in their future life.

\section{CONSTRUCTING COLLEGE NEW TEACHING QUALITY}

\section{MANAGEMENT MODE AND THE IMPORTANCE}

Management is the soul of development, and we shall emphasize the quality of the managers in college teaching quality management mode to guarantee the high-quality college education. Place emphasis to the people-oriented management system and adopt scientific and democratic management mode to improve college running level, give full play to the teachers to improve their teaching and management levels. The improvement of teaching quality and the management mode reform is the key to guarantee healthy, steady and sustainable development of colleges.

\section{THE MAJOR PROBLEMS TO BE EMPHASIZED IN CONSTRUCTING NEW TEACHING QUALITY MANAGEMENT MODE}

First, emphasize the standardization and objectivity of the management mode. Objectivity is the soul of realizing effective team management. The development of the college is realized through the standard management mode. To make sure healthy growth of the colleges, we must establish a management system with time effect, do well in division of labor, and bring all the staff into full positivity and pragmatic spirit. Second, emphasize the competitive and stimulating management system. Incentive is the important means to enhance the cohesive force of the whole faculty, and the incentive mechanism can be superior to all the college management mechanism. The teachers' emotion can be fully mobilized by the incentive mechanism, and at the same time, we shall introduce the appropriate competition mechanism, change the traditional management system, set the quality rewards and punishment system, bring the workers' subjective initiative into full play and get the staff into teaching and management posts with great enthusiasm. Third, emphasize the operability of the management system. A practical management mechanism is the one that can promote the college development, guarantee the quality teaching effects and improve the cohesive force of the staff. Set appropriate development objectivity and management system for each position and make correct evaluation on the teacher's work with performance management evaluation instrument to enhance the teacher's responsibility awareness and promote the healthy development of the management system. Last, emphasize the specific more of the incentive mechanism. Use salary as the effective mode for encouraging the college teachers to let them realize that salary is right the way of recognition for their work. Performance evaluation and flexible salary system can further mobilize the initiative of the teachers.

\section{THE SPECIFIC PROBLEMS IN COLLEGE TEACHING QUALITY MANAGEMENT MODE AT CURRENT STAGE}

\section{A. Not emphasize the student's cultural deposit in} college education management mode

The students tend to see a backward academic level earlier in colleges, since they have to learn a lot of knowledge in cultural curriculum and humanistic quality 
during their middle school while feel a relative relaxed tempo in colleges. The colleges and students pay not enough emphasis on their personal quality and refinement, and over the ling course, they will see a bad situation in cultural deposit and unfavorable impact on the future development of the college students.

B. The old teaching methods and content in college teaching management mode

At this stage, many college curriculum is still caught in the rigid mode, not emphasizing the communication and interaction between the teachers and students. That is not helpful for classroom positivity, and the lack of interest will have to impact the progress of study. in terms of teaching content, it also seems banal and empty. In the process of professional teaching, college teacher overemphasize the knowledge of the program, but ignore the education and cultivation of the students' comprehensive cultivation.

C. The college educational management mode not emphasizing shaping the students' outlook on life and values

Many college teachers cannot be fully thrown into the research and teaching activities under the influence of the external practice, but having too much emphasis on their own reputation and interests. Being at the unsteady stage of ideology and values, the students tend to be impacted by the teachers' practice, more harmful to the formation of their outlooks on life and values.

D. College education management mode lacks the cultivation on the student's innovation capacity

In classroom, if the college teachers use the traditional single teaching mode, the students will have their thoughts fixed in a unified mode, which will hinder their creative ability and have their positive thinking bonded, without much harmonious environment in classroom, and lack adequate teacher-student communication and interaction, quite unfavorable for the cultivation of the students' innovative ability.

\section{THE STRATEGY AGAINST THE PROBLEMS IN COLLEGE}

\section{EDUCATION MANAGEMENT MODE}

\section{A. Advocate the overall management to cultivate the} comprehensive quality of the students

While emphasizing the comprehensive ability, it is particularly important to spare a thought for the development of the student's career and ability. It is not enough just to have a strong professional knowledge and skills, instead, the students shall have a sound comprehensive ability to reach a favorable and recognized career. In the traditional teaching system, there is the lack of the cultivation for the students' comprehensive ability and quality. The students see a restriction for their future development. That requires further strengthening the students' creativity and emphasizing the students' cultural knowledge to achieve comprehensive development. They will see a better development only by improving the quality of their future study and life. Therefore, enhancing the overall teaching quality can make sure a smoother and more steady life for their future.

\section{B. Eliminate the old thought in teaching management mode}

The past teaching mode is a rigid and fixed traditional mode, not emphasizing the students' ability, without seeing cultivating the students' ability as the fundamental goal. Sheer emphasizing on learning professional knowledge will make each student the mechanism with high marks but adequate ability. To improve the students' ability and the passive situation, we must adapt to the new mode of teaching management and social development, build a student-centered teaching concept, pay attention to their creativity and innovation awareness, bring each student into classroom teaching, produce an active teaching atmosphere and cultivate their practice ability.

\section{Emphasizing the management on the students' outlook on life and values}

Teaching the college students how to develop their professional skills is part of the perfect teaching management, but the students shall also develop a mature and actual ability to suit the demands of the job career. Therefore, in the process of developing professional skill and students management, the colleges shall incorporate their outlooks on life and cultural values to stimulate their positivity, purify their soul and set study as the life-long passion. Only in this way, the students can more comprehensively and perfectly demonstrate their practice ability in the future no matter what difficulty they may face.

\section{Emphasizing the guidance of the innovative spirit in}

\section{the new teaching quality management mode}

In terms of teaching quality management mode, there lacks enlightening, exploration and discussion to cultivate the skeptical mind of the students. The traditional teaching mode is fixed only in, which is in bad need for improvement. To cultivate a group of high quality professional talents with creative mind, the college teaching management must endeavor to dig the creative potential of the students. Without innovation, there will not be development. It requires creating compelling plots in the selection of teaching environment to extend their emotions, stimulate their emotional resonance and help them acquire a specific feeling and correct understanding of the teaching content to further intensify their thinking and explorative ability. Improve the dull and banal situation of the college teaching quality, and only when there is harmonious classroom atmosphere, a sound classroom teaching mode and the divergent thinking mind of the students, can their creativity naturally improved.

\section{THE ADVICE FOR CONSTRUCTING A WHOLE NEW}

\section{COLLEGE TEACHING QUALITY MANAGEMENT MODE}

First, we shall guide the students to set the correct outlook on life and values, raise a higher educational goal to achieve a life-long benefits for the students, and even help them development a life tool for their future. Emphasize self-study and make sure the students can improve themselves by self-study whenever in their future life to realize life-long education. 
Second, we shall build a new college textbook mode. Based on the new scientific teaching rule, we shall emphasize the excellent part of the traditional teaching mode, and meanwhile, combine the new modern teaching concept, fully absorb the advanced teaching contents at home and aboard to reform our educational teaching. Emphasize the actual effect of the local college teaching system, positively conduct the teaching research and investigation and make brief conclusion to push the rapid development of curriculum reform and find out a new teaching management mode suitable to the our national actual situation within a short time.

Third, college teaching content shall first emphasize practice teaching. Practice can reflect the essence of the most prominent new function of modern teaching. College curriculum teaching effect can reflect the practical values at the largest degree. The interest can fully throw the students into classroom teaching and give full play to their initiative. While emphasizing the practicality, we shall also try to improve the scientific teaching and make the teaching content more scientific to achieve the final reform. All the students shall conform to the teaching materials, which shall in return, meet the demands of all the students with different basis and on different levels. To build a strong mass basis and make sure a smoother reform, we must make sure the true reform on teaching content.

Fourth, respect the subjective position of the students in the new teaching quality management mode, and improve their independent management capacity and self-management consciousness. College teaching quality management mode reform must have the individual development of the students as the fundamental objectivity, never relying too much on the years of serious management mode, or else, it would be inevitably hinder the development of the students' creativity and get them lose the interest in creation. In terms of curriculum arrangement, the teachers must emphasize the subjective initiative of the students and give them the chances to master the class. The teachers shall work with the students in increasing the curriculum contents to make sure the students can fully air their inner thoughts and reserve their opinions. This cannot only improve the teaching efficacy by making the students study on their own, and also truly improve the student's creativity. Modern education must hold people-oriented educational concept and bring into full play the students' imitative and positivity, improve the teachers' role in guidance, encourage the students to use their imaginative power to create more, doubt more and participate into more creative activities.

\section{CONCLUSION}

In summary, to achieve sustainable development in modern society, the colleges must pay attention to the reform and innovation on teaching quality management mode, adopt effective strategy to improve the overall management level of colleges. Only the perfect management system and sound management strategy can make sure an unimpeded development course for colleges. Therefore, we shall emphasize a new teaching quality management mode to promote the sustainable development of colleges.

\section{REFERENCE}

[1] System Philosophy and College Teaching Quality Guarantee System Construction and Research, Mu Kai, Zhongyuan University of Technology, 2013

[2] College Teaching Overall Quality Management System Construction and Composition in Our Country at Present, Liu Yongmei, Educational Teaching Forum, 2014

[3] Our College Undergraduate Practice Teaching System Research---Based on 12 Domestic Investigation Analysis, Xu Liang, Huaibei Normal University, 2013

[4] College Teaching Quality Guarantee Mechanism Research, Gu Xingqiang, East China Normal University, 2013

[5] Thinking on Constructing Teaching Quality Monitoring System, Dou Zhiqiang, Hengyang Normal College Journal, 2014

[6] Research on China's Vocational Education Teaching Quality Guarantee System Improvement---Based on the Perspective of Comprehensive Quality Management System Theory, Li Liying, Beijing Normal University, 2011.

[7] China's College Teaching Quality Monitoring System Construction and Practice Research at Present---with $\mathrm{X}$ University as the Example, Li Yingchun, Shanxi Normal University, 2015

[8] College Practice Teaching and Overall Quality Management Research, Xian Yao, Sichuan normal University, 2014

[9] China's Regular College Classroom Teaching Quality and Student Evaluation Indicator System Optimization Problem Research, Xie Bowen, Changsha University of Science and Technology, 2012

[10] College Modern Teaching Quality Evaluation System Reform and Construction Principle, Li Yangxi, Su Yuhui, Heilongjiang Education: Theory and Practice, 2015 